\title{
¿Para quién escribimos? Apuntes para una (im)posible respuesta
}

• Raúl Rodríguez Freire / Pontificia Universidad Católica de Valparaíso / rodriguezfreire@gmail.com

\section{Resumen}

Este texto pone en escena la transformación neoliberal de la universidad y la imposición de la lógica empresarial particularmente al ámbito de las humanidades, para, finalmente, dar cuenta de la potencia crítica del ensayo como forma.

Palabras clave: Universidad $•$ humanidades $•$ indexación - crítica · paper

\begin{abstract}
This text is about the neoliberal transformation of universities and the imposition of managerial logic particularly to the field of humanities, to finally underline the critical potency of the essay as form.
\end{abstract}

Key words: University $\cdot$ humanities $\cdot$ indexing $\cdot$ criticism • paper

\begin{abstract}
Yo, a pesar de que he escrito y publico bastante, no logro aún defenderme de una suerte de pudor, de decir, de declarar ¿por qué escribes? Parece que pensaras que lo que escribes es interesante. Lo llevas al editor, lo escribiste, entonces crees que las frases que elaboras son interesantes, lo que de alguna manera es absolutamente obsceno. El hecho de escribir es absolutamente injustificable desde ese punto de vista. Entonces, uno pide perdón, como alguien que se desnuda y dice "aquí está, miren», y naturalmente, pide de inmediato perdón. «Perdónenme por hacerme el interesante». Entonces, a partir del momento en que escribo, pido disculpas al otro e incluso al destinatario o a la destinataria, por la falta de pudor que hay en el hecho de escribir. JacQues Derrida, Por otra parte.
\end{abstract}

1.

Hace poco tiempo, en un diálogo sostenido con Nelly Richard, ella preguntaba por la posibilidad de que el arte y las humanidades representaran un bastión crítico frente a las transformaciones del trabajo intelectual, teniendo en cuenta lo que ella nombraba como «los avances globalizados de la tecnocracia del co- 
nocimiento». En lo que sigue, reescribiré la respuesta dada en aquella entrevista, en función por supuesto de la invitación que ahora nos realiza El taco en la brea.

\section{2.}

La pregunta por el lugar de las humanidades ronda como un espectro el siglo XXI. Y creo que la figura del espectro es la acertada, pues como tal retorna cada cierto tiempo, dado que nuestra época no es la única que se ha visto enfrentada a su desconsideración. Habría que comenzar, para ello, recordando la emergencia misma de lo que se ha dado en llamar universidad moderna, universidad instalada o replicada o remedada por todo el orbe, y por supuesto que con múltiples variaciones. Conocido es que dos son los modelos que, para Europa, la fundan: el napoleónico y el humboldtiano. Y ambos emergen, como recordó Friedrich A. Kittler 2004, al alero del desarrollo de una tecnología que terminaría enseñoreándose tecnocráticamente de la universidad. La temprana universidad moderna se había apoyado tan fuertemente en los libros impresos en todas sus multilingües interrelaciones que la emergencia más bien simultánea de dibujos de construcción técnicos, igualmente infalibles, escapó a su noticia. Letras, cifras y diagramas en su triple combinación probaron ser demasiado ajenos para los humanistas. La combinación, sin embargo, de tipos y grabados en madera o cobre permitió la visualización científica a un nivel de precisión inaudito para griegos y monjes. La tecnología como ciencia fue tan sólo el resultado siempre en expansión de esta alianza, y la Escuela Politécnica de Carnot y Monge, fundada en 1794 (llamada en ese entonces Escuela central de trabajos público), fue su más temprana instauración institucional. Y un brillante joven estudiante de todas estas matemáticas técnicamente aplicadas, un tal Bonaparte, invadió, equipado con la artillería pesada de Satanás, la vieja Europa. Desde esa época, recuerda Kittler, las universidades a ambos lados del Atlántico han tenido que vérselas con los ingenieros (248).

\section{3.}

De manera que las llamadas Escuelas Normales o Politécnicas, fundadas bajo una modernización liderada por Napoleón, le dieron a éste la oportunidad de rodearse de burócratas (los letrados de los que habla Kant en su hoy famoso texto universitario) y realizar las transformaciones de la universidad, roída aún por su herencia medieval. Lo mismo ocurrió en Alemania, si bien a partir de un modelo anclado a la firma de Humboldt, donde el Rey de Prusia «hizo funcionarios públicos a los profesores académicos y a los profesores de escuela secundaria, de forma que una dramáticamente modernizada facultad de filosofía pudiera inventar — por medio de seminarios dialógicos y conferencias hermenéuticas - la así llamada unidad de Forschung und Lehre (enseñanza e investigación)» (Kitler:248). De manera que la filosofía, pilar de la idea de universidad y de las humanidades en particular, en su versión moderna, de Hegel a Heidegger, debió acostumbrarse a tener por compañero de ruta el discurso ingenieril, encarnado en la palabra «ciencia». En otras palabras, ello quiere decir que la llamada universidad moder- 
na (y no desconozco toda su heterogeneidad) se transformó no en función del pensamiento, sino del rendimiento económico requerido por lo que se conocería como Revolución industrial, tal como lo deseó esa otra famosa Revolución llamada Francesa, con el matemático Condorcet a la cabeza, embelesado por el racionalismo y la técnica.

\section{4.}

En Chile, Andrés Bello fundó una Universidad donde la filosofía y las humanidades, antes de encargarse libremente de velar por «la verdad de las doctrinas» que se debían admitir racional y no gubernamentalmente, tenían por cometido la formación de un sujeto ad hoc a las políticas que implantaba el emergente Estado chileno. Es posible que Bello quisiera otra institución, como arguyen sus admiradores, pero en la práctica es esta la que tuvo lugar, por lo menos en sus inicios. Por ello su labor prioritaria fue la vigilancia de la política educativa nacional, la que se realizaría a través de una superintendencia. Además, la Facultad de Humanidades, al igual que las nacientes Facultades de Medicina, Leyes y Ciencias Matemáticas y Físicas, tenía entre sus cometidos generar las estadísticas nacionales de su respectiva área, y la estadística, vale recordar, es aquella herramienta que vendría a ocupar un lugar central en la biopolítica decimonónica de Occidente. La Universidad de Chile era entonces una universidad del Estado y para el Estado, que debía encarar los problemas económicos y políticos de la joven y creciente "población chilena». De manera que de este engendro salió de una lectura local, primero a partir del modelo instalado por Napoleón y luego, a contar del rectorado de Ignacio Domeyko (I879), que era químico de formación y profesión, siguiendo o intentando seguir la propuesta de Humboldt.

\section{5.}

En Chile, la emergencia de la universidad, pero imagino que no sólo en Chile, se da paralelamente al debate sobre el latín, pues creo que es en la disputa entre Ignacio Domeyko y Antonio Varas (seguida más tarde por Vicuña Mackenna y otros liberales), por incorporar, quitar o aminorar su enseñanza donde vemos el duro devenir que le esperaba a las humanidades. Para el primero, científico de tomo y lomo, el latín era la base de cualquier futuro educacional. El segundo, abogado y profesor de filosofía, pero chileno y provinciano a fin de cuentas, se interesaba más por el bienestar material de la nación, y lo hacía casi en los términos de hoy, defendiendo el lucro, pues es en la educación donde, para Varas (I843), aquel se encuentra «en el lugar que le corresponde». El Latín servía para la erudición, no para la ciencia, dirá el discípulo de Bello Gregorio Víctor Amunátegui (I857), el mismo que en su biografía sobre Domeyko recuerda que alrededor de I845 la precarización de los académicos era una constante, de manea que para paliar sus bajos ingresos se decretó un incentivo pecuniario a quienes publicaran o tradujeran textos que se emplearan en clases. ${ }^{1}$ Un incentivo, por cierto, similar al que hoy está «de moda» para aumentar la productividad académica, aunque el 
aula ya no es el espacio de su circulación, sino determinadas revistas ancladas al capitalismo financiero. ${ }^{2}$ Se trata, como vemos, de una forma de comprender el trabajo académico que no ha hecho su aparición de la mano del neoliberalismo, como se afirma de vez en cuando. Es consustancial a la universidad moderna. Patricio Marchant (1984) recordó en Sobre árboles y madres, libro cuya escritura, por cierto, es radicalmente heterogénea a la lingua franca de formato exigido por la mercado académica (el paper), que el mismo Heidegger, el pensador de la técnica, se vio sometido al ritmo fabril de la escritura.

Nombrado sucesor de Nicolai Hartmann en Hamburgo, el Ministerio Berlinés se opuso a su nombramiento: Heidegger no había publicado nada desde hacía diez años. Primeros envíos de Sein und Zeit al Ministerio, su rechazo por «insuficientes»; solo seis meses después de la publicación del texto completo, el Ministerio ratificó el nombramiento. ¿¿Simple hecho anecdótico? Más bien, ironía, esto es, necesidad de la historia; el filósofo que iba a denunciar la determinación técnica del pensar y del producir teórico tuvo que principiar, por acatar, sin embargo, las exigencias del pensar determinado por la técnica: si no producir apresuradamente, al menos publicar apresuradamente.

Entonces, más que un simple hecho anecdótico, la historia de la extraña publicación de Sein und Zeit adelantaba los tiempos actuales, la práctica actual de la filosofía: escribir según las exigencias de producción de la Universidad, esto es, de las fuerzas exteriores a la Universidad que a la universidad rigen; pues, sin duda, pocas instituciones menos libres en la sociedad contemporánea que la universidad. Así, situación de la filosofía, hoy: abandono del pensar como constitución de una obra, como fidelidad a un único pensamiento o como trabajo de escritura; su sustitución por la indigencia teóricamente organizada de los papers, discusión de problemas mínimos por mínimos profesores; esto es, la interpretación técnica del pensar como la filosofía determinante de las universidades occidentales. (8I)

\section{6.}

Cito y seńalo todo esto para recordar que las humanidades históricamente han estado asediadas, y no siempre desde su exterior. Max Hokheimer ya había resaltado en su famoso ensayo sobre la teoría crítica que incluso las ciencias del espíritu tienen «un fluctuante valor de mercado» (226) y más de un siglo antes Hegel hacía referencia - en sus Lecciones sobre la historia de la filosofía - a las filosofías de moda $(45){ }^{3}$ Sé que cada tiempo tiene sus propias particularidades, pero es necesario evitar algo así como un narcisismo de actualidad para entrever no tanto una comprensión del gobierno del presente, siempre necesaria ética y políticamente, como vislumbrar las posibilidades de su transformación.

\section{7.}

Por ello creo que el gran problema con el que nos enfrentamos es precisamente la dificultad de pensar el futuro, de escribirlo o reescribirlo, y esto en todo el mundo, pues habitamos de manera fundamentalista el presente. Y aquí la escritura crítica y la ficción teórica deben tener un lugar relevante donde quiera que tengan 
lugar, pues aún guardan la potencia para performar un mundo heterogéneo a este que nos han impuesto, un mundo en el que la mitologización, en el sentido de Barthes, parece ser la norma, tal como lo comprueba el uso acrítico de las nociones de calidad, excelencia, capital humano, crédito, etc., que han sido vaciados en pos de una razón económica. El Barthes de las Mitologías (20I0) le llamaría a esto la transformación de la historia en naturaleza, que hace que tales vocablos se usen de manera inocente, como si no tuvieran historia y fueran neutrales, no técnicos, y pudieran sustraerse a la argumentación, a no tener que dar explicaciones y entregarse al conformismo de lo dado, pues, ¿quién podría estar contra la calidad? Pero el saber no es suficiente. La crítica de esta mitologización es una parte de un ejercicio mayor: la transformación de nosotros mismos. En tanto práctica material, la crítica debe encargarse tanto de desmantelar las categorías que nos constituyen, que nos producen, como en fortalecer una ética de sí que permita la desujeción al capital humano, al emprendimiento, a la vanidad, a nuestros egos, etc. Nietzsche señalaba que sólo como obra de arte de justifica la existencia, lo cual quiere decir que debemos crearnos a nosotros mismos, inventar estilos heterogéneos, y dejar de recurrir a los manuales que te dicen cómo llevar tu vida, cómo escribir una tesis, cómo un paper; en definitiva, se trata dejar a los expertos de lado, y ponerse a experimentar.

\section{8.}

Hasta ahora, la crítica, cuando se plantea como interrupción, ha estado fundamentalmente preocupada por develar las condiciones de sujeción de los «otros», desconsiderando la sujeción que ella misma, que nosotros mismos, vivimos, por ejemplo, al seguir el juego del éxito académico, las modas teóricas, de la publicación indexada, el paper como forma de escritura, etc. Creo, por último, que la crítica, encarnada en sujetos particulares, debe también reconocer un cierto fracaso. La crítica no ha logrado armar comunidades discursivas de debate, no ha logrado articularse como un colectivo beligerante, sino que ha seguido el mismo derrotero que el neoliberalismo le ha marcado: la fragmentación radical. Cuando reconozcamos la urgencia de dejar nuestros egos de lado, la crítica podrá comenzar a reconstituirse. El curador José Falconi, un excéntrico de la crítica por lo demás, señaló en algún lugar que cuando viaja a Chile participa por lo menos de tres asados, porque sus amigos no se juntan entre sí, a pesar de que todos se conocen (aunque lo mismo pasa en otros países). Para sobrevivir, la crítica debe recomponerse de manera colectiva, discutiendo y debatiendo, lo que no quiere decir que haya que ser amigo de todo el mundo, ni abolir nuestras diferencias. El disenso es la condición o por lo menos una de las condiciones de la política.

\section{9.}

La intensión entonces de preguntarse para quién escribimos adquiere una relevancia política de primer orden ahora que las humanidades están literalmente siendo obligadas a clausurar. Bajo este escenario, la forma del ensayo adquiere 
relevancia para el trabajo del pensamiento, al enfrentar un tipo de escritura académica que niega la imaginación teórica y crítica al imponer como requisito una forma fija y repetitiva. Cualquier paper repite por lo menos tres o cuatro veces las ideas principales, y las famosas palabras clave, junto al respectivo resumen, condicionan la lectura como el peor de los paratextos, aunque se las requiere para asegurar supuestamente su rápida recepción y consumo. Pero lo cierto es que ello (el consumo) tampoco es así. Dos académicos, Asit K. Biswas y Julian Kirchherr (2015), publicaron hace poco un estudio en el diario virtual For The Straits Times, donde seńalaban que, para el caso de las humanidades, el $82 \%$ de los artículos publicados en revistas con referato externo (peer-reviewed) nunca son citados (aunque abundan las autocitas). La pregunta que surge entonces es ¿para quién se está escribiendo? Si se es complaciente con lo que Marchant llamaba la interpretación técnica del pensar la respuesta no es muy difícil de encontrar: para las empresas que lucran con sus bases de datos que venden a precios exorbitantes a las universidades donde nosotros mismos trabajamos, bases de datos que las agencias acreditadoras prácticamente obligan a subscribir, pues es una de las variables a considerar cuando se mide la calidad bibliográfica de una universidad. Creo que Harvard u otra universidad de la Ivy League se quejó en algún momento del costo de estas bases, que se llevaban casi la mayor parte del presupuesto de sus bibliotecas. Así las cosas, la escritura del ensayo (y la defensa de las revistas independientes) adquiere un carácter político, al situarse a contrapelo de una escritura que prácticamente se resiste a pensar y se la intenta imponer como el modelo por excelencia de la reflexión académica.

\section{0.}

Acatar la interpretación técnica del pensar equivale a pensar técnicamente, productivamente, obliterando el tiempo que requiere el trabajo del pensamiento, un tiempo fagocitado por la velocidad a la que se nos obliga cuando se toma por medida el trabajo de las llamadas ciencias duras, acostumbradas por lo general a medir su impacto por la cantidad de citas que genera una publicación reciente. Por el contrario, en las humanidades, la relevancia de una publicación crece con el tiempo. Incluso se diría que gráficamente tienen caminos distintos, pues un artículo científico tiene una resonancia que con los años decrece. ${ }^{4}$ De manera que no podemos aceptar el juego del factor de impacto $u$ otras mediciones que son incapaces de dar cuenta de una escritura que se levanta a contrapelo de la tecnificación y la productividad. Tal escenario obliga a preguntarse no sólo para quién escribimos, sino también y de manera fundamental cómo escribimos. Se trata de una interrogante que le da su fuerza política al ensayo, forma que, como escribió Martín Cerda 1982, no busca “"ex-poner” una visión o un saber total (y muchas veces "totalitario"), sino, introducir una mirada discontinua en un mundo que, en lo mas sustantivo, se oculta o se enmascara con diferentes ropajes y lenguajes "totales": monolíticos y opresivos» (13). Esos ropajes y lenguajes son los del artículo académico o paper, que alisan lo estriado que contiene una escritura que 
se resiste a las palabras claves, esto es, a los lenguajes comunes y disciplinados. Potencia que se nubla cada vez que nos encontramos con la palabra ensayo refiriendo textos tecnificados, cuadriculados, mutilados, en función de dar cuenta de algún resultado de investigación.

\section{1.}

Para quién y cómo escribimos entonces. Escribimos, aventuro, para uno mismo, por uno mismo, pues es nuestro ego el que primero aflora en el juego de las vanidades académicas y no académicas. Unos con pudor, otros sin ninguno. Pero ahí, o aquí, en estas mismas líneas, está nuestra exhibición, sostenida sobre las palabras de otro, cuestión que borra, así sea parcialmente, ese (este) ego levantado sobre los egos de otros, y la vergüenza entonces se parte, o se comparte. Y ahora que sabemos que no hacemos más que recomenzar una escritura milenaria, independientemente de la lengua, pues toda escritura siempre es varias, miles escrituras, podemos decir que escribimos para otros que no conocemos, pero en los cuales confiamos: alumnos, amigos, colegas, pasados, presentes y futuros. $Y$ lo que les confiamos es la inseguridad de (lo) que escribimos. En cuanto al cómo, aventuro nuevamente: solo el ensayo y su forma nos pueden devolver esa seguridad con la que no contamos al momento de querer escribir. ¿Y cuál es hoy esa seguridad? La que nos dice, sin ninguna garantía, que no solo se está escribiendo para uno mismo, que se está escribiendo para otros con los cuales se desea transformar el mundo, partiendo por el pequeño mundo académico, que no tiene juego, que no experimenta, que no ensaya, ese mundo que publica papers que nadie o casi nadie lee. Por el contrario, el ensayo es una forma que, como dijo Alfonso Reyes 1996, «no puede ya responder al orbe circular y cerrado de los antiguos, sino a la curva abierta, al proceso en marcha» (400) de nuestra propia transformación, individual y colectivamente.

Viña del Mar, junio/agosto de 2016

Notas

${ }^{1}$ Este incentivo proviene de un decreto supremo fechado el I4 de enero de I845. Diecisiete años más tarde, un tal José Antonio Varas, Capitán del ejército y autor de Recopilación de leyes, decretos supremos i circulares concernientes al ejército, solicita al Consejo de la Universidad de Chile que recomiende al Gobierno dar también este incentivo «a los militares que escriban libros para la enseńanza del ejército». No lo sé, pero es posible que la respuesta a dicha solicitud haya sido aprobada, razón por la cual Pinochet, alguna vez profesor de geopolítica en la Academia de Gue- rra de Chile, publicó alrededor de una docena de libros bajo su nombre. Otra cosa es que los haya escrito él.

2 Thomson Reuters, la empresa que domina la gestión y almacenamiento de revistas académicas, acaba de formar una alianza económica con la empresa china Horizon Software (que asume el control de tal alianza), «líder mundial de tecnología para el comercio electrónico y la gestión de inversiones», según indica su página web.

${ }^{3}$ «[E]l nombre de filosofía nueva, moderna, novísima, se ha convertido en una especie de nombre de guer- 
ra, que se escucha a todas horas. Quienes creen decir algo al pronunciar este nombre son, casi siempre, los que más se inclinan a santiguarse y echar bendiciones ante la muchedumbre de las filosofías, tanto más cuanto más propenden, bien a ver un sol en cada estrella y hasta en cada vela, bien a considerar toda ocurrencia como una filosofía y a aducirla, por lo menos, en prueba de que existen muchísimas filosofías y de que todos los días aparece una que desplaza a las anteriores. Han inventado, al mismo tiempo, la categoría en que pueden colocar toda filosofía que parece adquirir cierta significación y con la que, al mismo tiempo, pueden deshacerse de ella; la llaman, simplemente, una filosofía a la moda» (Hegel:45).

${ }^{4}$ La temporalidad del trabajo literario y filosófico fue algo que conversamos con el filósofo Martín Ríos.

\section{Bibliografía}

Barthes, Roland (20I0). Mitologías. Buenos Aires: Siglo xxi. Traducido por Héctor Schmucler.

Biswas Asit K. y Julian Kirchherr (2015) «Prof, no one is reading you» [en línea]. The Straits

Times. Consultado el 22 de mayo de 2015 en http://www.straitstimes.com/opinion/prof-noone-is-reading-you.

Cerda, Martín (1982). La palabra quebrada. Valparaíso: Ediciones Universitarias de Valparaíso.

Hegel, G.W.F (1995). Lecciones sobre historia de la filosofía. Vol. I. México: Fondo de Cultura Económica. Traducido por Wenceslao Roces.

Horkheimer, Max (1937). "Teoría crítica». Teoría crítica. Buenos Aires: Amorrortu, 2008. Traducido Edgardo Albizu y Carlos Luis.

Kittler, Friedrich A. (2004). «Universities: Wet, Hard, Soft, and Harder». Critical Inquiry 3I.I, 244-255.

Marchant, Patricio (1984). Sobre árboles y madres. Santiago: Gato Murr.

Reyes, Alfonso (1996). «Las nuevas artes». Obras completas. Vol. Ix. México: Fondo de Cultura Económica, 400-403. 